\title{
Investigation of Chlamydophila spp. in dairy cows with reproductive disorders
}

\author{
Ann-Charlotte Godin*1, Camilla Björkman¹, Stina Englund², Karl- \\ Erik Johansson $^{3,4}$, Rauni Niskanen ${ }^{1}$ and Stefan Alenius ${ }^{1}$
}

Address: ${ }^{1}$ Division of Ruminant Medicine and Veterinary Epidemiology, Department of Clinical Sciences, Faculty of Veterinary Medicine and Animal Science, Swedish University of Agricultural Sciences (SLU), Box 7054, SE-750 07, Uppsala, Sweden, ${ }^{2}$ Department of Animal Health and Antimicrobial strategies, Section of Antibiotics, National Veterinary Institute (SVA), SE-751 89, Uppsala, Sweden, ${ }^{3}$ Division of Bacteriology and Food Safety, Department of Biomedical Sciences and Veterinary Public Health, Faculty of Veterinary Medicine and Animal Science, Swedish University of Agricultural Sciences (SLU), Box 7009, SE-750 07, Uppsala, Sweden and ${ }^{4}$ Department of Bacteriology; National Veterinary Institute (SVA), SE-751 89, Uppsala, Sweden

Email: Ann-Charlotte Godin* - Ann-Charlotte.Godin@kv.slu.se; Camilla Björkman - Camilla.Bjorkman@kv.slu.se;

Stina Englund - Stina.Englund@sva.se; Karl-Erik Johansson - Karl-Erik.Johansson@bvf.slu.se; Rauni Niskanen - Rauni.Niskanen@slv.se;

Stefan Alenius - Stefan.Alenius@kv.slu.se

* Corresponding author

Published: 26 September 2008

Acta Veterinaria Scandinavica 2008, 50:39 doi:10.1I86/I75I-0I47-50-39

This article is available from: http://www.actavetscand.com/content/50/I/39

(C) 2008 Godin et al; licensee BioMed Central Ltd.

This is an Open Access article distributed under the terms of the Creative Commons Attribution License (http://creativecommons.org/licenses/by/2.0), which permits unrestricted use, distribution, and reproduction in any medium, provided the original work is properly cited.

\begin{abstract}
Background: Reports worldwide indicate high prevalence of Chlamydophila spp. infection in cattle. To assess the prevalence in Sweden, 525 cows in 70 dairy herds with reproductive disorders was investigated.
\end{abstract}

Methods: To detect antibodies two commercially available kits were used. Moreover, 107 specimens, including vaginal swabs, organ tissues and milk were analysed by Polymerase Chain Reaction (PCR).

Results: Two $(0.4 \%)$ cows were seropositive in the Pourquier $C$. abortus ELISA. The seroprevalence with the Chekit ELISA was $28 \%$ with no difference between cases and controls. Five specimens were positive in real-time PCR and further analysed by nested PCR. Cp. pecorum was confirmed by partial omp/ DNA sequencing of the nested PCR product of vaginal swabs from control cows.

Conclusion: The results suggest that $C p$. abortus infection is absent or rare in Swedish cows whereas $C p$. pecorum is probably more spread. They also suggest that Chlamydophila spp. are not related to reproduction disorders in Swedish cattle.

\section{Background}

Chlamydia are obligate, intracellular, gram-negative bacteria that cause a wide range of diseases in humans, other mammals and birds. The two species Chlamydophila (Cp.) abortus (formerly Chlamydia (C.) psittaci serotype 1) and Cp. pecorum (formerly C. pecorum) are known to infect ruminants [1]. It has also been reported that $C p$. psittaci may infect cattle [2-4]. In many sheep-producing countries Cp. abortus is known to cause Ovine Enzootic Abortion (OEA) [5]. The zoonotic potential of Cp. abortus is well known and poses a threat to mainly pregnant women, handling sheep and goats [6]. Chlamydial infec- 
tion in cattle has been associated with reproductive disorders including abortion, endometritis, repeat breeding, vaginitis, seminal vesiculitis, weak calves and perinatal mortality [7-11]. Moreover, symptoms such as pneumonia, conjunctivitis, enteritis, polyarthritis and encephalitis have been reported [12-14]. It has been suggested that both Cp. abortus and Cp. pecorum are ubiquitous in cattle $[10,15,16]$.

Reproductive disorders and infertility are major causes of culling in dairy herds. The diagnostic rate of abortions is usually below 35\% $[17,18]$. In Sweden, 97\% of all dairy herds are free of Bovine viral diarrhoea virus (BVDV) [19] and the prevalence of Neospora (N.) caninum infection is $2 \%$ [20]. Furthermore, Sweden is free from Brucella abortus, Leptospira spp. and Bovine herpes virus 1 (IBR/IPV) [21]. The prevalence of chlamydial infections and their effect on reproduction in Swedish cattle is unclear and has not previously been investigated. The aim of this study was therefore to investigate the prevalence of antibodies against Chlamydophila spp., preferably Cp. abortus and the occurrence of chlamydial agents in Swedish dairy herds with a history of reproductive disorders.

\section{Methods}

Animals and samples

Seventy dairy herds from different parts of Sweden that experienced reproductive disorders, mainly abortions, during January 2000 to December 2006 were included in this study. Herd sizes ranged from 19 to 215 cows and all herds were free of BVDV and N. caninum. As part of the diagnosis investigations, blood samples were collected by local veterinarians and sent by mail to the laboratory. Samples were collected from 4 to 15 cows (average 7.5, median 6), >2 years of age from each herd, except in two herds where all cows, 32 and 34, respectively, were bled. In almost all herds (61/70) samples from both cows with clinical signs (cases) and cows with normal pregnancies and parturitions (controls) were taken, and in the other nine herds only cows with clinical signs were sampled. A total of 525 animals were blood sampled: 286 cases and 239 controls. Of the 286 cases, 179 had aborted (twothirds during the last trimester). They were bled on the same day or up to 10 months after abortion (mostly within the first 3 months after abortion). The other cases had premature parturition or parturition at full term resulting in death, stillbirth or weak neonate, repeat breeding or vaginitis. The blood samples were centrifuged at $1000 \times g$ for 10 minutes and sera collected and stored at $-20^{\circ} \mathrm{C}$ until analysis.

Vaginal swabs (Cytobrush Plus, Medscand Medical AB), milk samples, placentas and organs from aborted foetuses were also collected from some of the herds. In total 107 specimens were submitted: 43 vaginal swabs (from 31 cases and 12 controls in 12 herds), 54 milk samples (37 cases and 17 controls, in 10 herds), organs from 5 aborted foetuses in 3 herds and 5 placentas from abortions in 5 herds. Samples were stored at $-70^{\circ} \mathrm{C}$ prior to preparation and analysis.

\section{Detection of antibodies to Chlamydophila abortus}

Two commercially available Cp. abortus antibody detection kits were used.

The Pourquier ELISA Chlamydophila abortus serum verification test (Institut Pourquier) uses a recombinant fragment of an 80-90 kDa polymorphic outer membrane protein as antigen. The kit was used according to the manufacturer's instructions, where $\mathrm{S} / \mathrm{P} \%$ values equal or more than 100 are considered as positive for cattle.

The CHEKIT-Chlamydia enzyme immunoassay (Dr. Bommeli AG-Idexx) is based on an inactivated antigen originally isolated from a case of abortion in sheep. The test was performed according to the instructions of the manufacturer, considering corrected optical density (OD\%) values $>40$ as positive.

\section{Detection of Chlamydiaceae by Polymerase Chain Reaction (PCR)}

DNA was extracted from vaginal swabs for PCR analysis according to the protocol by Sachse and Hotzel [22]. For tissue specimens and milk the High Pure Template Preparation kit (Roche Diagnostics) was applied, following the manual provided by the manufacturer, with a slight modification for milk samples [16].

Analyses were made by a real-time PCR, developed by Everett et al. [23] which targets the 23S ribosomal DNA and detects the family Chlamydiaceae. The sensitivity of the test was estimated by spiking samples prior to DNA extraction with 10 -fold dilutions of $C p$. abortus (inactivated strain S26/3 in original concentration of $3 \times 10^{8}$ IFU/ml, kindly provided by D. Longbottom, Moredun Research Institute, UK). The sensitivity was estimated to 1 IFU/PCR for all specimens except milk where the sensitivity was $10 \mathrm{IFU} / \mathrm{PCR}$.

Positive samples by the real-time PCR were further analysed for species identification by a nested PCR as described by Kaltenboeck et al. [24] and modified by Sachse and Hotzel [22]. The nested PCR targets the omp1 gene and identifies the four species C. trachomatis, C. psittaci, C. pecorum and C. pneumoniae, according to the old classification.

\section{DNA sequence analysis of the PCR products}

Amplicons from the nested PCR were purified prior to sequencing by the GFX PCR DNA and Gel Band Purifica- 
tion Kit (Amersham Bioscience Europe). The PCR products were then sequenced with primers 204 pecor and chomp 336 [22] and with the BigDye Terminator v3.1 Cycle Sequencing Kit (Applied Biosystems) in combination with ethanol/EDTA/sodium acetate precipitation according to the protocol of the manufacturer. Thermocycling was performed in a GeneAmp 2700 Thermocycler (Applied Biosystems). The sequencing products were subjected to electrophoretic separation and on-line detection on an ABI PRISM 3100 Genetic Analyzer (Applied Biosystems), followed by computerized sequence evaluation (BLAST search).

\section{Statistics}

The chi-square test was used for Chekit ELISA results to calculate significance $\left(\right.$ Minitab $^{\circledR}$ Release 14.2, Minitab Inc.).

\section{Results}

\section{Antibody assays}

Of 525 blood sampled cows, only two (0.4\%) were seropositive in the Pourquier Cp. abortus ELISA (S/P\% values
154 and 114, respectively). They originated from two different herds. One cow had aborted in the last trimester and the other had experienced premature parturition. Most of the samples were well clustered far below the cutoff value $100 \%$; only 6 samples ( 4 cases and 2 controls) had $\mathrm{S} / \mathrm{P} \%$ values above 60 , the recommended cut-off value for sheep sera (Figure 1).

The seroprevalence with the Chekit ELISA was 28\% (148/ $525)$ and the prevalence did not differ between cases (81/ $286)$ and controls (67/239). OD\% values for positives ranged between $41-369 \%$ (Figure 2). In $81 \%$ (57/70) of the herds at least one sampled cow was positive. Of the 179 cases of abortion, antibodies were detected in 55 cows (31\%). The two cows seropositive in the Pourquier $C p$. abortus ELISA were both seronegative in the Chekit assay (OD\% value 3 and 21, respectively).

PCR

Chlamydiaceae was detected by real-time PCR in vaginal swabs from 2 out of 12 control cows but not from any of the 31 cases. Cp. pecorum was detected in both swabs by

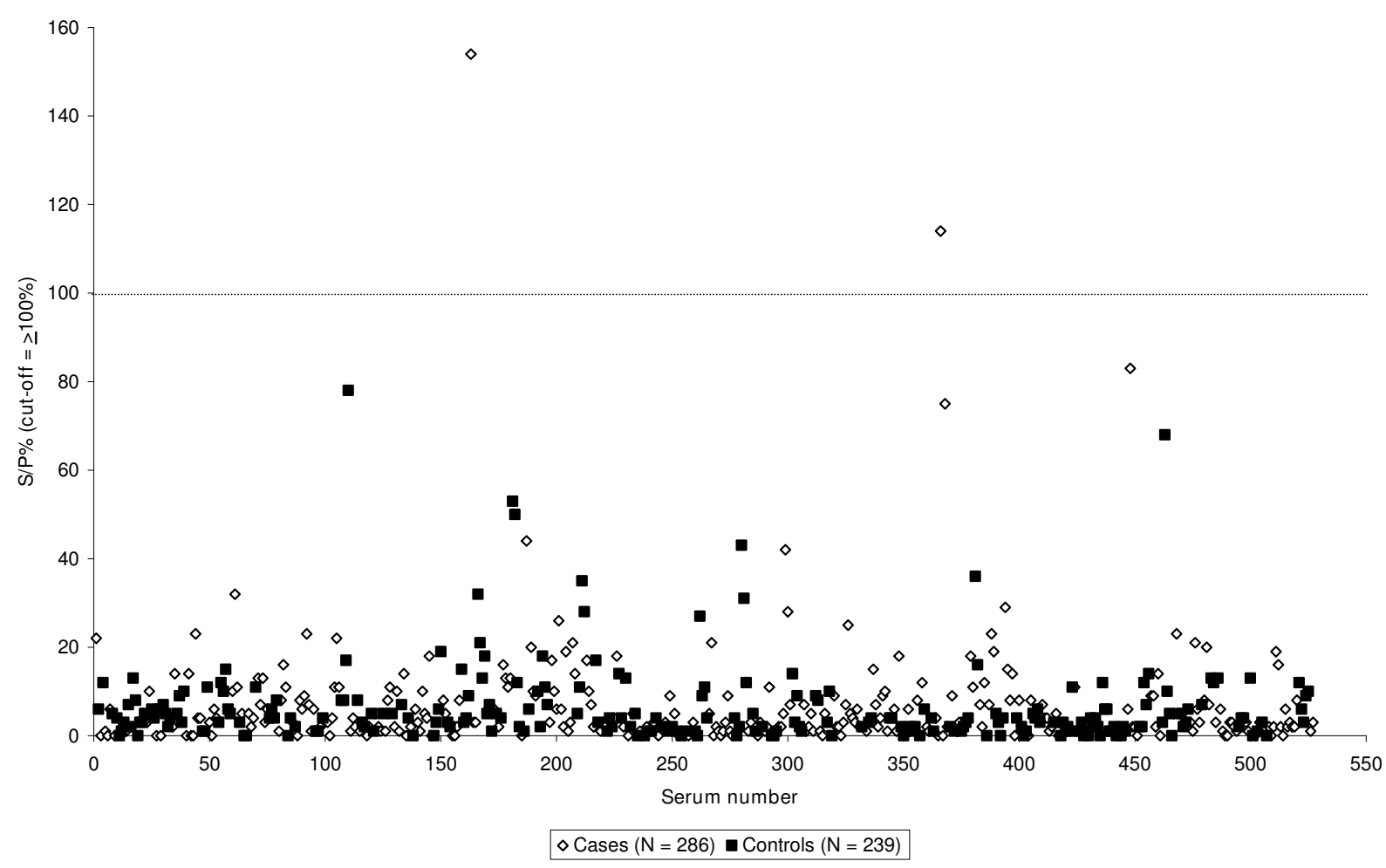

Figure I

Results of Pourquier ${ }^{\circledR}$ Cp. abortus ELISA serology in 525 Swedish dairy cows from 70 herds with reproductive disorders, sampled during January 2000 to December 2005. The dotted line shows the cut-off value. The seroprevalence among cases was $0.4 \%(2 / 286)$ and among controls $0 \%$. 


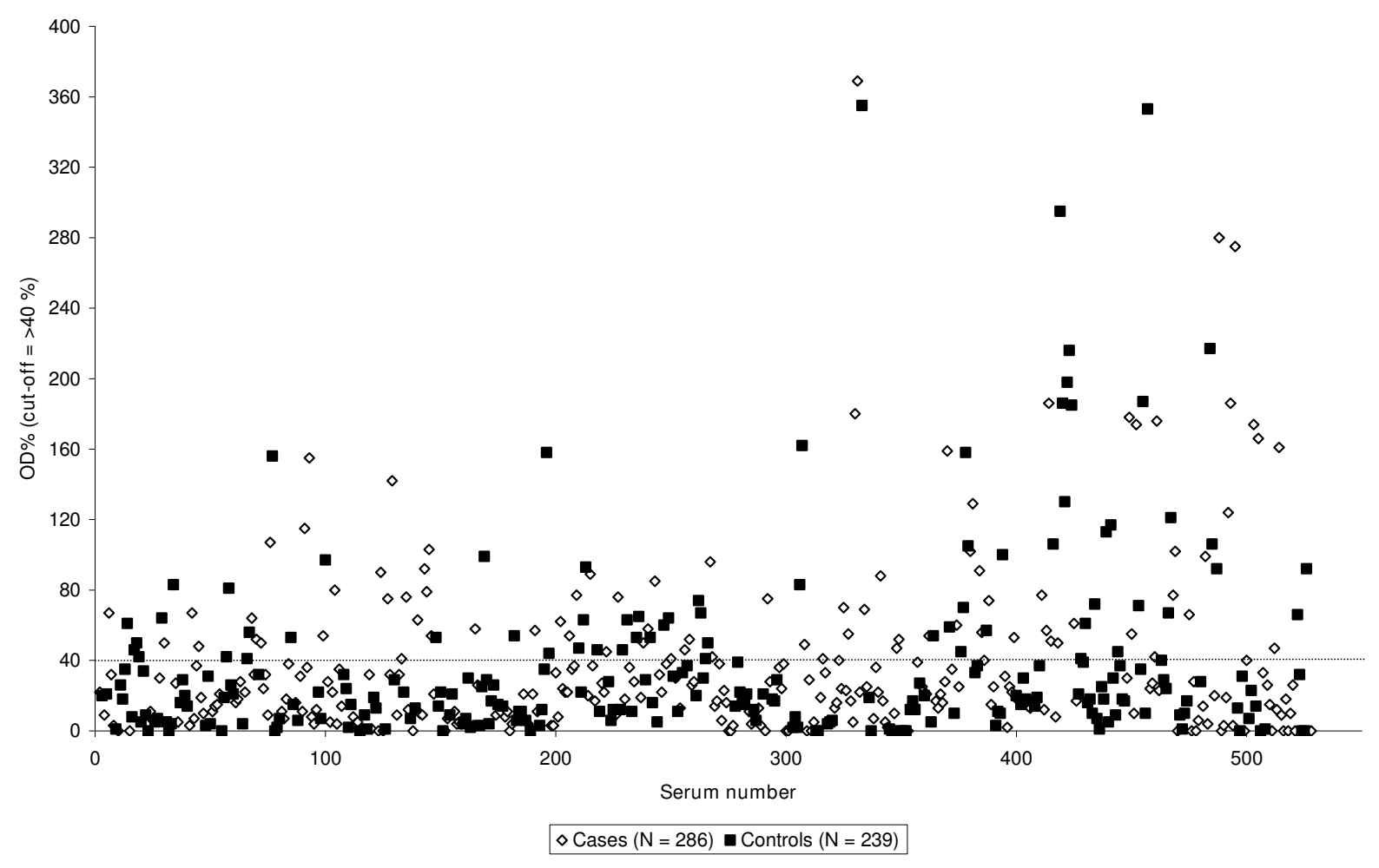

Figure 2

Results of $\mathrm{CHEKIT}^{\circledR}{ }_{-}$-Chlamydia enzyme immunoassay serology in $\mathbf{5 2 5}$ Swedish dairy cows from 70 herds with reproductive disorders, sampled during January 2000 to December 2005. The dotted line shows the cut-off value. The seroprevalence among cases was $28 \%(81 / 286)$ and among controls $28 \%(67 / 239)$.

nested PCR and further confirmed by partial omp1 DNA sequencing of the PCR product. The two cows came from different herds and were both negative in the Pourquier Cp. abortus ELISA and positive in the Chekit ELISA (OD\% values 100 and 295).

Three more Chlamydiaceae positive samples were identified: a placenta from an aborting cow that was not serologically tested, and two milk samples from cows that had aborted and were negative in both antibody tests. These samples were all negative in the nested PCR, probably due to lower sensitivity of this test, and could not be sequenced. The placenta was collected in one of the herds that had a $C p$. pecorum positive vaginal swab and the milk samples came from two other herds.

\section{Discussion}

The results of this first investigation of Chlamydophila spp. infection in Swedish dairy cows suggest that Cp. abortus infection is absent or rare in Sweden. Only two samples were positive in the Pourquier ELISA. These might well be false positive results because both samples were negative in the Chekit assay, which is based on an antigen containing lipopolysaccharide shared by several Chlamydiaceae, including Cp. abortus. Even if we had applied the lower cut-off value used for sheep sera, only six samples would have been positive in the Pourquier ELISA, of which all except one, were negative in the Chekit ELISA. The specificity of the Pourquier ELISA has been reported to be 100\% when analysed Scottish sheep documented free of OEA [25] and 90\% when sera from New Zealand, a country free from Cp. abortus, were analysed [26].

The seroprevalence obtained in our study with Chekit ELISA probably represents antibodies against $C p$. pecorum because it is known to infect cattle and we identified $C p$. pecorum in vaginal swabs from two Chekit ELISA positive cows. In a recent Austrian investigation, the majority of blood sampled cows from which vaginal and cervical swabs also were taken and found $C p$. pecorum positive by PCR, were seropositive by Chekit ELISA [27]. Further, the Chekit ELISA reacted with positive results in $26 \%$ out of 15 sera from SPF lambs immunized with Cp. pecorum [25]. We found no difference in Chekit ELISA seroprevalences 
between cows with reproductive problems, including abortion, and healthy control cows. This is in concordance with the Austrian study where no correlations between reproductive problems and Chekit ELISA or PCR positivities were found [27]. However, significantly higher seroprevalences among aborting versus healthy cows have been reported in some other studies applying the Chekit ELISA test $[28,29]$. Additionally, in an investigation of German herds with diverse fertility disorders, no difference in seropositivity was observed between the group of apparently healthy cows and the group of cows with abnormal reproductive performance. However, a significantly higher proportion of the cows that had aborted were seropositive [11].

The absence, or very low prevalence, of Cp. abortus in Swedish dairy cows could be due to the small mean herd size of 44 animals (year 2005) and that most are kept tethered during a nine-month stable period, with little contact within the herd. Further, the tradition of self-contained herds, the sparsely populated Swedish countryside with few external contacts and little movement of animals across country, give few animals a chance to get infected. The absence or very low prevalence could also be due to a generally lower infection pressure owing to lack of other infections, e.g. BVDV. Another explanation could be that Cp. abortus infection seems to be very low in Swedish sheep. In a recent investigation, including 800 sheep sera from different parts of Sweden, only 3 sera were positive with the Pourquier $C p$. abortus ELISA (unpublished data).

\section{Conclusion}

This investigation suggests that infections with Cp. abortus are absent or rare in Swedish cows whereas Cp. pecorum are probably more spread. It also suggests that Chlamydophila spp. is not related to reproduction disorders in Swedish cattle.

\section{Competing Interests}

The authors declare that they have no competing interests.

\section{Authors' contributions}

ACG drafted and rewrote the manuscript, carried out the PCR and serology analysis, interpreted the results and performed the statistical analysis. CB and SA conceived and designed the study, and participated in its coordination. SE implemented the PCR systems and carried out the sequencing analysis. KEJ participated in the sequencing analysis. All authors participated in the design of the study and have been involved in revising the manuscript.

\section{Acknowledgements}

We thank Maj Hjort for technical assistance with the serological analyses. The study was supported by the Swedish Farmer's Foundation for Agricultural Research and the Programme for Infection Biology at the Veterinary
Faculty, Swedish University of Agricultural Sciences. It was part of the EU research collaboration COST 855.

\section{References}

I. Everett KDE: Chlamydia and Chlamydiales: more than meets the eye. Vet Microbiol 2000, 75:109-126.

2. Cox HU, Hoyt PG, Poston RP, Snider TG 3rd, Lemarchand TX, O'Reilly KL: Isolation of an avian serovar of Chlamydia psittaci from a case of bovine abortion. J Vet Diagn Invest 1998, I 0:280-282.

3. Borel N, Thoma R, Spaeni P, Weilenmann R, Teankum K, Brugnera E, Zimmermann DR, Vaughan L, Pospischil A: Chlamydia-related abortions in cattle from Graubunden, Switzerland. Vet Pathol 2006, 43:702-708.

4. Kauffold J, Henning K, Bachmann R, Hotzel H, Melzer F: The prevalence of chlamydiae of bulls from six bull studs in Germany. Anim Reprod Sci 2007, 102: I I - 121.

5. Aitken ID: Chlamydial abortion. In Diseases of Sheep 3rd edition. Edited by: Martin WB, Aitken ID. Edinburgh: Blackwell; 2000:8I-86.

6. Longbottom D, Coulter LJ: Animal chlamydioses and zoonotic implications. J Comp Pathol 2003, I 28:2 17-244.

7. Storz J: Overview of animal diseases induced by chlamydial infections. In Microbiology of Chlamydia Edited by: Barron AL. Florida: CRC Press, Inc; 1988:167-192.

8. Daniel RG, Holliman A, David GP, Kirby FD, Simpson VR, Cranwell MP, Dawson M, Griffiths PC, Bevan BJ: Bovine chlamydiosis in the United Kingdom. Vet Rec 1993, I 33:351-352.

9. Wittenbrink MM, Schoon HA, Bisping W, Binder A: Infection of the bovine female genital tract with Chlamydia psittaci as a possible cause of infertility. Reprod Dom Anim 1993, 28:129-136.

10. Kaltenboeck B, Hehnen HR, Vaglenov A: Bovine Chlamydophila spp. infection: do we underestimate the impact on fertility? Vet Res Comm 2005, 29: I-I5.

II. Wehrend A, Failing K, Hauser B, Jager C, Bostedt H: Production, reproductive, and metabolic factors associated with chlamydial seropositivity and reproductive tract antigens in dairy herds with fertility disorders. Theriogenology 2005, 63:923-930.

12. Piercy DW, Griffiths PC, Teale C): Encephalitis related to Chlamydia psittaci infection in a I4-week-old calf. Vet $\operatorname{Rec} 1999$, 144: | 26- I28.

13. Otter A, Twomey DF, Rowe NS, Tipp JW, McElligott WS, Griffiths $P C$, O'Neill P: Suspected chlamydial keratoconjunctivitis in British cattle. Vet Rec 2003, I 52:787-788.

14. Twomey DF, Griffiths PC, Hignett BC, Martin TP: Suspected chlamydial polyarthritis in a calf in the UK. Vet $\operatorname{Rec} 2003$, I 52:340.

15. De Graves FJ, Gao D, Hehnen HR, Schlapp T, Kaltenboeck B: Quantitative detection of Chlamydia psittaci and $C$. pecorum by high-sensitivity real-time PCR reveals high prevalence of vaginal infection in cattle. J Clin Microbiol 2003, 4I:I726-1729.

16. Jee J, De Graves FJ, Kim T, Kaltenboeck B: High prevalence of natural Chlamydophila species infection in calves. J Clin Microbiol 2004, 42:5664-5672.

17. Alves D, McEwen B, Hazlett M, Maxie G, Anderson N: Trends in bovine abortions submitted to the Ontario Ministry of Agriculture, Food and Rural Affairs, 1993-1995. Can Vet J 1996, 37:287-288.

18. Cabell E: Bovine abortion: aetiology and investigations. In Practice 2007, 29:455-463.

19. Hult L, Lindberg A: Experiences from BVDV control in Sweden. Prev Vet Med 2005, 72:143-148. 215-219.

20. Björkman C, Alenius S, Emanuelsson U, Uggla A: Neospora caninum and bovine virus diarrhoea virus infections in Swedish dairy cows in relation to abortion. Vet J 2000, I 59:20 I-206.

21. De Verdier K, Persson Waller K: [Abortion in cows - a warning signal that should be investigated (author's transl)]. Svensk Veterinärtidning 2003, I 2: 17-24.

22. Sachse K, Hotzel H: Detection and differentiation of Chlamydiae by nested PCR. Methods Mol Biol 2003, 2 I 6:123-136.

23. Everett KDE, Hornung LJ, Andersen AA: Rapid detection of the Chlamydiaceae and other families in the order Chlamydiales: Three PCR tests. J Clin Microbiol I 999, 37:575-580.

24. Kaltenboeck B, Schmeer N, Schneider R: Evidence for numerous ompl alleles of porcine Chlamydia trachomatis and novel 
chlamydial species obtained by PCR. J Clin Microbiol 1997, 35:|835-|84I.

25. Vretou E, Radouani F, Psarrou E, Kritikos I, Xylouri E, Mangana O: Evaluation of two commercial assays for the detection of Chlamydophila abortus antibodies. Vet Microbiol 2007, 123:153-161.

26. McCauley LM, Lancaster MJ, Young P, Butler KL, Ainsworth CG: Comparison of ELISA and CFT assays for Chlamydophila abortus antibodies in ovine sera. Aust Vet J 2007, 85:325-328.

27. Petit T, Spergser J, Aurich J, Rosengarten R: Prevalence of Chlamydiaceae and Mollicutes on the genital mucosa and serological findings in dairy cattle. Vet Microbiol 2008, 127:325-333.

28. Cavirani S, Cabassi CS, Donofrio G, De laco B, Taddei S, Flammini CF: Association between Chlamydia psittaci seropositivity and abortion in Italian dairy cows. Prev Vet Med 200I, 50:I45-I5I.

29. Wang Fl, Shieh H, Liao YK: Prevalence of Chlamydophila abortus infection in domesticated ruminants in Taiwan. J Vet Med Sci 200I, 63:12I5-I220.

Publish with Biomed Central and every scientist can read your work free of charge

"BioMed Central will be the most significant development for disseminating the results of biomedical research in our lifetime. "

Sir Paul Nurse, Cancer Research UK

Your research papers will be:

- available free of charge to the entire biomedical community

- peer reviewed and published immediately upon acceptance

- cited in PubMed and archived on PubMed Central

- yours - you keep the copyright

Submit your manuscript here:

http://www.biomedcentral.com/info/publishing_adv.asp 